\title{
Implementation of an optimal stomatal conductance scheme in the Australian Community Climate Earth Systems Simulator (ACCESS1.3b)
}

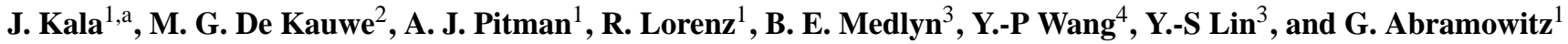 \\ ${ }^{1}$ Australian Research Council Centre of Excellence for Climate Systems Science and Climate Change Research Centre, \\ University of New South Wales, Sydney, NSW, 2052, Australia \\ ${ }^{2}$ Macquarie University, Department of Biological Sciences, Sydney, Australia \\ ${ }^{3}$ Hawkesbury Institute for the Environment, University of Western Sydney, Sydney, Australia \\ ${ }^{4}$ CSIRO Ocean and Atmosphere Flagship, Aspendale, Victoria 3195, Australia \\ a now at: Murdoch University, School of Veterinary and Life Sciences - Environmental and Conservation Sciences, Murdoch, \\ 6150, WA, Australia
}

Correspondence to: J. Kala (j.kala@murdoch.edu.au, jatin.kala.jk@gmail.com)

Received: 19 May 2015 - Published in Geosci. Model Dev. Discuss.: 3 July 2015

Revised: 8 October 2015 - Accepted: 25 November 2015 - Published: 8 December 2015

\begin{abstract}
We implement a new stomatal conductance scheme, based on the optimality approach, within the Community Atmosphere Biosphere Land Exchange (CABLEv2.0.1) land surface model. Coupled land-atmosphere simulations are then performed using CABLEv2.0.1 within the Australian Community Climate and Earth Systems Simulator (ACCESSv1.3b) with prescribed sea surface temperatures. As in most land surface models, the default stomatal conductance scheme only accounts for differences in model parameters in relation to the photosynthetic pathway but not in relation to plant functional types. The new scheme allows model parameters to vary by plant functional type, based on a global synthesis of observations of stomatal conductance under different climate regimes over a wide range of species. We show that the new scheme reduces the latent heat flux from the land surface over the boreal forests during the Northern Hemisphere summer by $0.5-1.0 \mathrm{~mm}$ day $^{-1}$. This leads to warmer daily maximum and minimum temperatures by up to $1.0^{\circ} \mathrm{C}$ and warmer extreme maximum temperatures by up to $1.5^{\circ} \mathrm{C}$. These changes generally improve the climate model's climatology of warm extremes and improve existing biases by 10-20\%. The bias in minimum temperatures is however degraded but, overall, this is outweighed by the improvement in maximum temperatures as there is a net improvement in the diurnal temperature range in this region. In other regions such as parts of South and North
\end{abstract}

America where ACCESSv1.3b has known large positive biases in both maximum and minimum temperatures $(\sim 5$ to $10^{\circ} \mathrm{C}$ ), the new scheme degrades this bias by up to $1^{\circ} \mathrm{C}$. We conclude that, although several large biases remain in $\mathrm{AC}$ CESSv1.3b for temperature extremes, the improvements in the global climate model over large parts of the boreal forests during the Northern Hemisphere summer which result from the new stomatal scheme, constrained by a global synthesis of experimental data, provide a valuable advance in the longterm development of the ACCESS modelling system.

\section{Introduction}

Stomata control the exchange of water vapour and carbon between the vegetation and the atmosphere. The coupling of the energy, water and carbon exchange at the leaf level was a profoundly important step in the development of land surface models (LSMs; Sellers et al., 1996). Accurately capturing these exchange processes in LSMs is critical since they affect the terrestrial water, energy and carbon balances (Pitman, 2003). Early studies at the point scale have illustrated the potential impact of stomatal behaviour on local meteorology (e.g. Jacobs and De Bruin, 1992; Raupach, 1998; Huntingford and Monteith, 1998). This has prompted a num- 
ber of investigations showing impacts at both the global (e.g. Henderson-Sellers et al., 1995; Pollard and Thompson, 1995) and regional (e.g. Avissar and Pielke, 1991; Martin et al., 1999; Cruz et al., 2010) scales. Recent studies have also shown that the different physiological response of tropical forests to increasing $\mathrm{CO}_{2}$ is a larger source of uncertainty in estimating future carbon stocks than the future emission scenarios (Huntingford et al., 2013). Similarly, other studies suggest that physiological adaptations of subtropical vegetation to increasing $\mathrm{CO}_{2}$ could account for reductions in the annual transpiration flux of up to $\sim 60 \mathrm{~W} \mathrm{~m}^{-2}$ in some regions (de Boer et al., 2011). Given these large impacts, there is currently an urgent need to explore accurate representations of stomatal behaviour suitable for implementation in LSMs within general climate models (Huntingford et al., 2015).

It is common in LSMs (e.g. Sellers et al., 1992; Bonan, 1995; Cox et al., 1998; Wang et al., 2011) to represent stomatal conductance $\left(g_{\mathrm{s}}\right)$ using an empirical model (Jarvis, 1976; Ball et al., 1987; Leuning, 1995). Whilst parameters for these empirical models can easily be calibrated using experimental data, in practice they rarely are. Instead, the current suite of LSMs, including the Community Atmosphere Biosphere Land Exchange (CABLE; Wang et al., 2011), only differentiate model parameters by photosynthetic pathway (C3 vs. C4) (Krinner et al., 2005; Oleson et al., 2013), rather than by plant functional type (PFT). Medlyn et al. (2011) proposed an alternative approach, deriving a stomatal conductance scheme from optimal stomatal theory. This approach maintains the same functional form as the empirical models but attaches a theoretical meaning to the model parameters. Parameters now represent a plant's water use strategy and thus can be hypothesised to vary across climate space. Lin et al. (2015) used a global database of $g_{\mathrm{s}}$ data to show that stomatal behaviour varied between PFTs as predicted by the optimal stomatal theory (and the leaf and wood economic spectrum), in line with the Medlyn et al. (2011) model. De Kauwe et al. (2015) tested an implementation of this $g_{\mathrm{s}}$ scheme within CABLE using flux tower observations and global offline forcing and showed $\mathrm{a} \sim 30 \%$ reduction in annual fluxes of transpiration compared to the standard CABLE model across boreal, tundra and $\mathrm{C} 4$ grass regions.

This paper extends on the work of De Kauwe et al. (2015) in several ways. CABLE is the LSM used in the Australian Climate and Earth Systems Simulator (ACCESS; Bi et al., 2013), a global climate model that performed very well in comparison with observations within the Coupled Model Intercomparison Project (CMIP-5; Flato et al., 2013). Our first goal is to test the feasibility of using the De Kauwe et al. (2015) implementation of the Medlyn et al. (2011) stomatal conductance scheme globally, within the ACCESS coupled land-atmosphere climate model. De Kauwe et al. (2015) showed that the new scheme generally improved CABLE's performance in offline experiments, forced by prescribed meteorology and evaluated using observations. Our second goal is to determine whether this improved performance is sus- tained in the coupled environment of the ACCESS model. ACCESS has a satisfactory control climate in terms of means (Bi et al., 2013; Kowalczyk et al., 2013), but Lorenz et al. (2014) examined the model's climatology in terms of some extremes linked with the land surface and showed serious problems in the simulation of the diurnal temperature range due to biases in both maximum and minimum temperatures. These were, in part, attributed to an overestimation of evapotranspiration linked to weaknesses in the representation of land processes. We seek to determine whether the biases identified by Lorenz et al. (2014) can be resolved in part via the parameterization of $g_{\mathrm{s}}$.

\section{Methods}

\subsection{Model description}

We use the Australian Community Climate Earth System Simulator version 1.3b (ACCESSv1.3b). The set-up follows Lorenz et al. (2014) and consists of the atmospheric Unified Model (UMv7.3; Davies et al., 2005; Martin et al., 2006) and CABLEv2.0.1 operated in an Atmospheric Model Intercomparison Project (AMIP; Gates, 1992) configuration with prescribed sea surface temperatures and sea ice fractions. These were sourced from the Program for Climate Model Diagnosis and Comparison (Taylor et al., 2000) and re-gridded and converted to the Unified Model data format. We performed simulations at $1.25^{\circ}$ latitude by $1.875^{\circ}$ longitude resolution (N96 resolution), with 38 vertical levels, and a 30 min time step. Further details of the ACCESS model can be found in Bi et al. (2013) and Lorenz et al. (2014).

\subsection{New stomatal conductance scheme}

The implementation of the new $g_{\mathrm{s}}$ scheme was documented by De Kauwe et al. (2015), and we only provide a brief description here. The default stomatal conductance to water vapour $g_{\mathrm{s}}\left(\mathrm{mol} \mathrm{H}_{2} \mathrm{Om}^{-2} \mathrm{~s}^{-1}\right)$ scheme in CABLE is based on Leuning (1995):

$g_{\mathrm{s}}=g_{0}+\frac{a_{1} \beta A}{\left(C_{\mathrm{s}}-\Gamma\right)\left(1+\frac{D}{D_{0}}\right)}$,

where $A$ is the net assimilation rate $\left(\mu \mathrm{mol} \mathrm{m}{ }^{-2} \mathrm{~s}^{-1}\right) ; C_{\mathrm{s}}$ $\left(\mu \mathrm{mol} \mathrm{mol}{ }^{-1}\right)$ and $D(\mathrm{kPa})$ are the $\mathrm{CO}_{2}$ concentration and the vapour pressure deficit at the leaf surface, respectively; $\Gamma$ ( $\mu \mathrm{mol} \mathrm{mol}{ }^{-1}$ ) is the $\mathrm{CO}_{2}$ compensation point of photosynthesis; $g_{0}=0.01 \mathrm{~mol} \mathrm{H}_{2} \mathrm{O} \mathrm{m}^{-2} \mathrm{~s}^{-1} ; D_{0}(\mathrm{kPa})$ and $a_{1}=9$ (conductance to $\left.\mathrm{CO}_{2}\right) \times 1.6$ (the ratio of molecular diffusivity of $\mathrm{H}_{2} \mathrm{O}$ to $\mathrm{CO}_{2}$ ) $=14.4$ (conductance to $\mathrm{H}_{2} \mathrm{O}$ ) are fitted constants representing the residual stomatal conductance as the assimilation rate reaches zero, the sensitivity of stomatal conductance to $D$, and the sensitivity of stomatal conductance to assimilation, respectively. In CABLE, the fitted parameters $g_{0}$ and $a_{1}$ vary with photosynthetic pathway (C3 vs. C4) but 
Table 1. Fitted $g_{1}$ values for the PFTs shown in Fig. 1.

\begin{tabular}{lr}
\hline PFT & $g_{1}\left(\mathrm{kPa}^{0.5}\right)$ \\
\hline Evergreen needleleaf & 2.35 \\
Evergreen broadleaf & 4.12 \\
Deciduous needleleaf & 2.35 \\
Deciduous broadleaf & 4.45 \\
Shrub & 4.70 \\
C3 grassland & 5.25 \\
C4 grassland & 1.62 \\
Tundra & 2.22 \\
C3 cropland & 5.79 \\
\hline
\end{tabular}

not PFT, and $D_{0}$ is fixed for all PFTs. $g_{0}$ is scaled from the leaf to the canopy by accounting for leaf area index, following Wang and Leuning (1998). $\beta$ represents an empirical soil moisture stress factor:

$\beta=\frac{\theta-\theta_{\mathrm{w}}}{\theta_{\mathrm{fc}}-\theta_{\mathrm{w}}} ; \beta[0,1]$,

where $\theta$ is the mean volumetric soil moisture content $\left(\mathrm{m}^{3} \mathrm{~m}^{-3}\right)$ in the root zone, $\theta_{\mathrm{w}}$ is the wilting point $\left(\mathrm{m}^{3} \mathrm{~m}^{-3}\right)$ and $\theta_{\mathrm{fc}}$ is the field capacity $\left(\mathrm{m}^{3} \mathrm{~m}^{-3}\right)$.

In this study we replaced Eq. (1) with the $g_{\mathrm{s}}$ model of Medlyn et al. (2011) and the same $\beta$ factor as above:

$g_{\mathrm{s}}=g_{0}+1.6\left(1+\frac{g_{1} \beta}{\sqrt{D}}\right) \frac{A}{C_{\mathrm{s}}}$,

where $g_{1}\left(\mathrm{kPa}^{0.5}\right)$ is a fitted parameter representing the sensitivity of the conductance to the assimilation rate. In this formulation of the $g_{\mathrm{s}}$ model, the $g_{1}$ parameter has a theoretical meaning:

$g_{1} \propto \sqrt{\frac{\Gamma^{*}}{\lambda}}$,

where $\lambda\left(\mathrm{molC} \mathrm{mol}^{-1} \mathrm{H}_{2} \mathrm{O}\right)$ is the marginal carbon cost of water use and $\Gamma^{*}\left(\mu \mathrm{mol} \mathrm{mol}{ }^{-1}\right)$ is the $\mathrm{CO}_{2}$ compensation point in the absence of mitochondrial respiration. As a result, $g_{1}$ is inversely related to the marginal carbon cost of water (Medlyn et al., 2011).

Values of $g_{1}$ for the CABLE PFTs (Fig. 1) are shown in Table 1. These have been compiled from a global database of stomatal conductance from 314 species across 56 field sites (Lin et al., 2015) including Arctic tundra, boreal, temperate forests and tropical rainforest biomes. Further details can be found in De Kauwe et al. (2015). In addition to differences in parameterisation between the two $g_{\mathrm{s}}$ models (i.e. $g_{0}, g_{1}$ ), the models also have contrasting sensitivities to $D$. Further details can be found in De Kauwe et al. (2015); in short, over low to moderate values of $D(<1.5 \mathrm{kPa})$, the $g_{\mathrm{s}}$ simulated by the new scheme is more sensitive to $D$. By contrast, at higher values of $D(>2 \mathrm{kPa}), g_{\mathrm{s}}$ simulated by the default model are more sensitive to increasing $D$ than the new model.

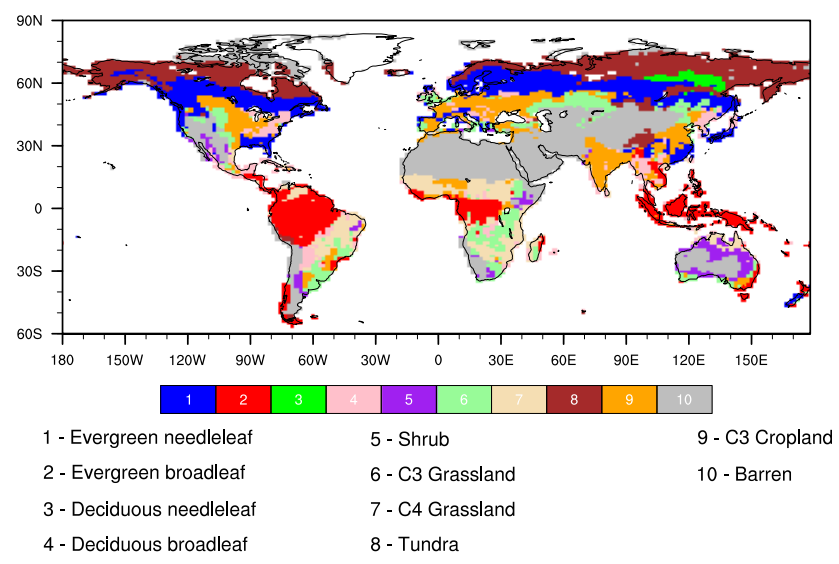

Figure 1. Distribution of dominant PFTs across the model domain.

Finally, we note that for both schemes in CABLE, $A$ and $g_{\mathrm{s}}$ are solved iteratively. Additionally, for the MED scheme, $g_{0}=0 \mathrm{~mol} \mathrm{H}_{2} \mathrm{Om}^{-2} \mathrm{~s}^{-1}$, meaning that $g_{\mathrm{s}}$ goes to zero under low light and, importantly, high $D$ conditions. By contrast, in the default LEU scheme, $g_{0}=0.01$ and $0.04 \mathrm{~mol} \mathrm{H}_{2} \mathrm{O} \mathrm{m}^{-2} \mathrm{~s}^{-1}$ for $\mathrm{C} 3$ and $\mathrm{C} 4$ species, respectively.

\subsection{Simulations}

Two sets of simulations were carried out, the control simulation using the default Leuning (1995) scheme (LEU, Eq. 1) and the experiment using the Medlyn et al. (2011) scheme (MED, Eq. 3). ACCESS1.3b simulations cover the period 1950-2012. The first 10 years were used as a spin-up period and are not included in the analysis. Five ensembles were carried out for each simulation, initialised a year apart, so that the impact of natural model variability is reduced and any signal from the change in $g_{\mathrm{s}}$ is clear relative to internal model noise. Results are shown averaged over these five ensembles. The initial conditions are the same as those used by Lorenz et al. (2014).

We note that whilst CABLE has the ability to incorporate carbon pool dynamics (i.e. time varying foliage, wood and roots biomass) as a function of nitrogen and phosphorus limitations (Wang et al., 2010), these features were not used here. Instead, similar to the experimental set-up of Lorenz et al. (2014), a monthly leaf area index (LAI) climatology derived from MODIS (Moderate Resolution Imaging Spectroradiometer) estimates was used. This was deliberate to allow for a comparison with Lorenz et al. (2014) and, additionally, as a first step it is critical to first isolate the biophysical effects of the new $g_{\mathrm{s}}$ scheme before considering the combined biophysical and biogeochemical effects.

\subsection{Benchmarking data sets}

We use a similar benchmarking data sets to those employed by Lorenz et al. (2014) in a prior evaluation of the AC- 

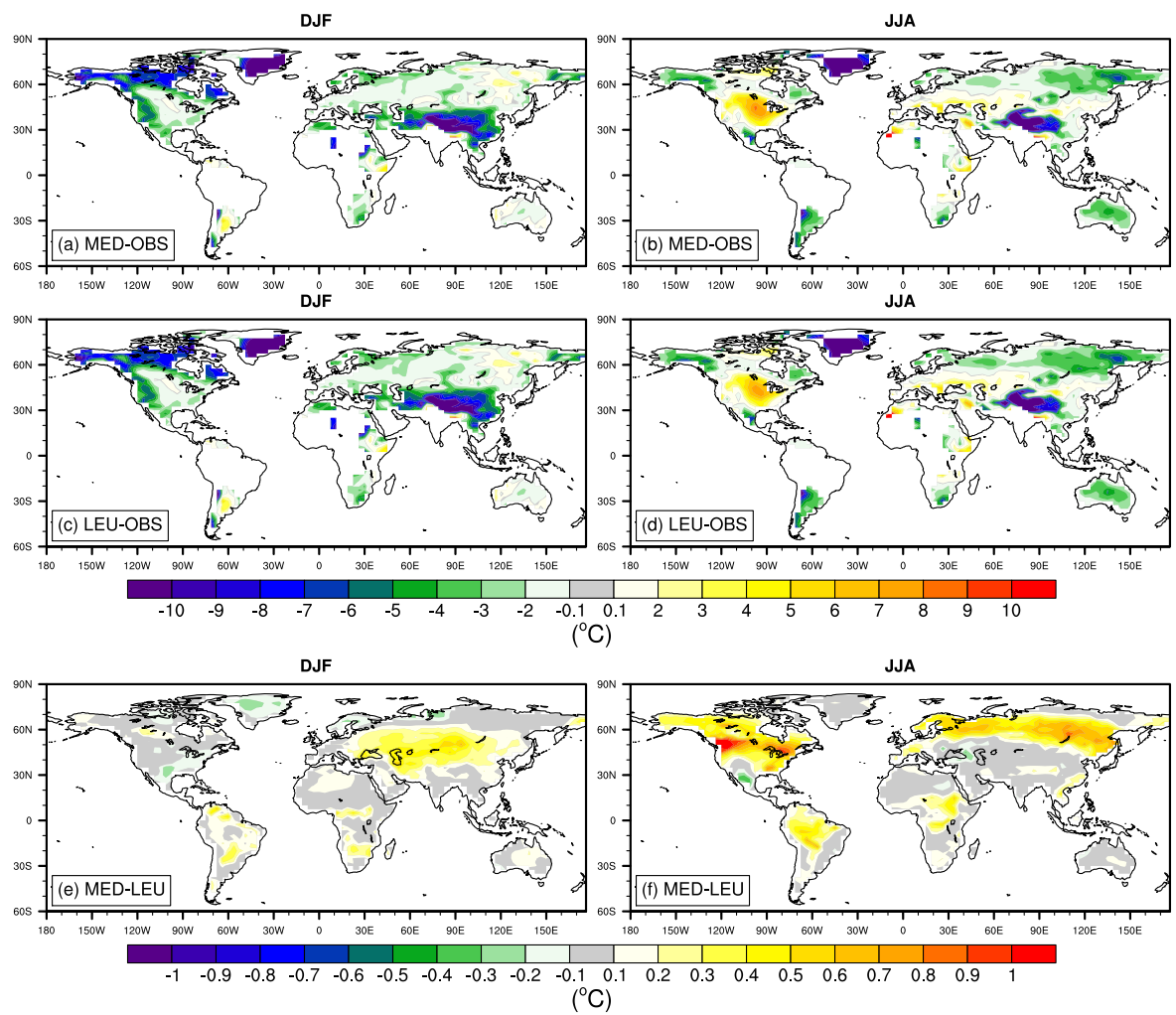

Figure 2. (a-d): mean seasonal difference in maximum temperature ( $T_{\text {MAX }}$ ) between the MED and LEU experiments and the HadGHCND data set (OBS) during boreal summer (JJA, left panels) and winter (DJF, right panels). (e-f): difference between the MED and LEU simulations. Seasonal means are computed over the period 1960-2010. Inland areas in white for panels (a-d) represent missing data.

CESS1.3b climatology of both the mean and extremes of temperature and precipitation.

Maximum $\left(T_{\mathrm{MAX}}\right)$ and minimum $\left(T_{\mathrm{MIN}}\right)$ temperatures were obtained from the HadGHCND gridded daily temperature data set (Caesar et al., 2006), which is derived from nearsurface maximum and minimum temperature observations from 1951 to present at a $2.75^{\circ}$ latitude by $3.75^{\circ}$ longitude resolution. We also used the Expert Team on Climate Change Detection and Indices (ETCCDI; http://www.climdex.org/ indices.html), which are derived from daily $T_{\mathrm{MAX}}$ and $T_{\mathrm{MIN}}$. The indices chosen for this study include the warmest seasonal maximum $\left(T_{X x}\right)$ and the diurnal temperature range (DTR; the amplitude between $T_{\mathrm{MAX}}$ and $T_{\mathrm{MIN}}$ ). These indices are from the HadEX2 data set and described in detail by Donat et al. (2013). These indices were chosen as Lorenz et al. (2014) highlighted significant under-estimation of $T_{\mathrm{MAX}}$ and over-estimation of $T_{\mathrm{MIN}}$, leading to an underestimation of the DTR. The ACCESS results were interpolated to the HadGHCND domain prior to comparison as they are at a higher resolution. Seasonal means of $T_{\mathrm{MAX}}, T_{\mathrm{MIN}}$, DTR and $T_{X x}$ were computed over the period 1960-2010.

We also tested the influence of the new scheme on precipitation using the Global Precipitation Climatology Project (GPCP) data set version 2 (http://www.esrl.noaa.gov/psd/ data/gridded/data.gpcp.html). This data set is derived from a combination of satellite and rain-gauge measurements and is available at a $2.5^{\circ}$ latitude by $2.5^{\circ}$ longitude resolution. The ACCESS precipitation was interpolated to the GPCP grid and seasonal means were computed over the period 1979-2011.

Finally, given the influence of $g_{\mathrm{s}}$ on the exchange of water vapour from vegetation to the atmosphere, we assess the influence of the new scheme on total evapotranspiration (ET). While there are no direct observations of ET available at the global scale, the LandFlux-EVAL data set (Mueller et al., 2013) provides a comprehensive ensemble of global ET estimates at a $1^{\circ}$ latitude by $1^{\circ}$ longitude resolution, derived from various satellites, LSMs driven with observationally based forcing and atmospheric re-analysis. We used data over the period 1989-2005, and the LandFlux ET product was interpolated to the ACCESS domain as it is at a higher resolution.

For all comparisons of ACCESS against the various data sets, seasonal means were computed from each of the five ensembles separately, then averaged for comparison. 

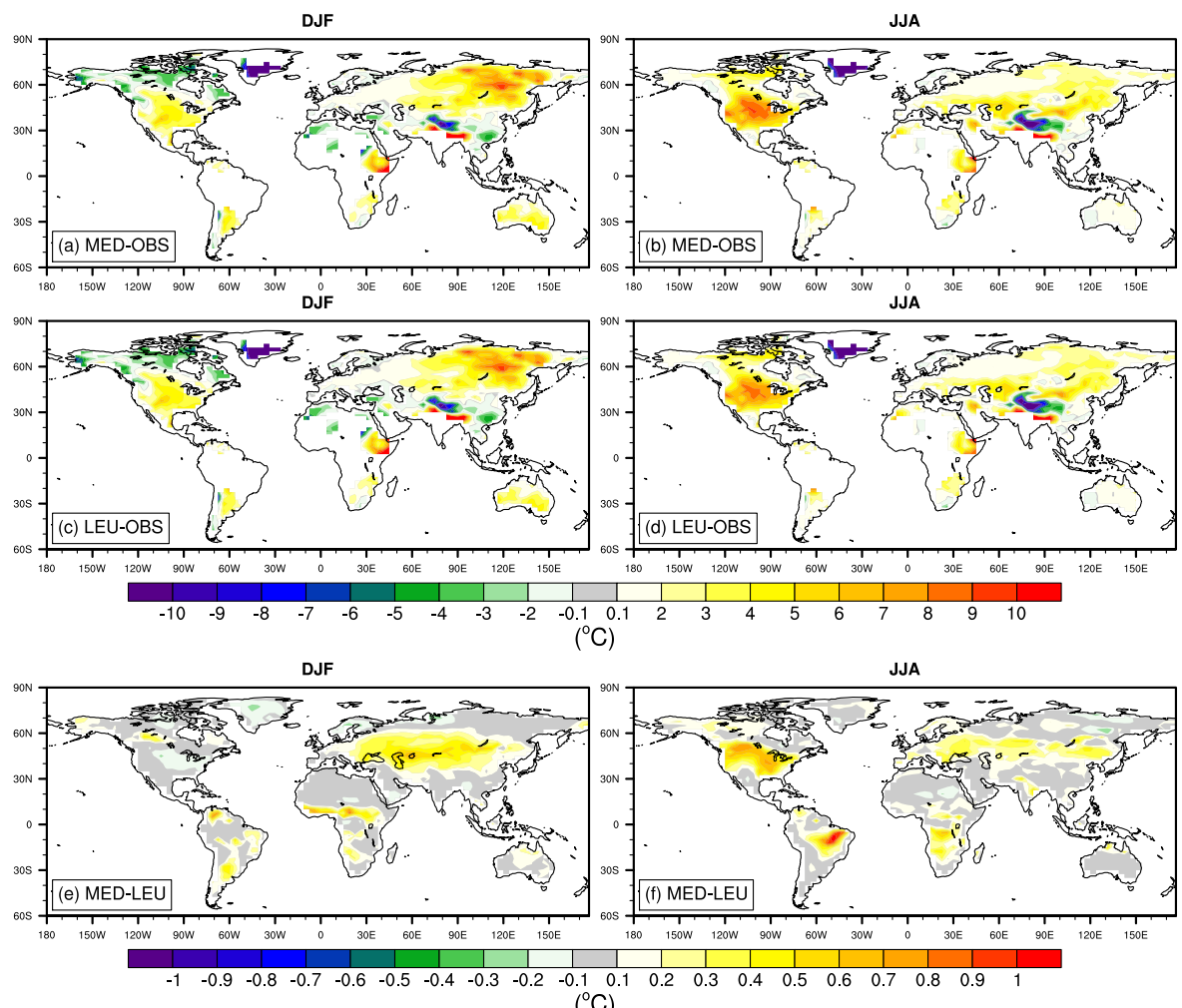

$\left({ }^{\circ} \mathrm{C}\right)$

Figure 3. Same as in Fig. 2 except for minimum temperature ( $\left.T_{\mathrm{MIN}}\right)$.

\section{Results}

Figure 2 shows the seasonal mean differences in $T_{\mathrm{MAX}}$ during the boreal winter (December-January-February, DJF) and summer (June-July-August, JJA) between the MED and LEU simulations and observations over the period 19602010 (panels a-d), as well as the differences between the MED and LEU simulations (panels e, f). All results are averaged across the five ensembles. The two climatologies from the ACCESS1.3b model are very similar and show similar large-scale biases. There are, for example, large biases over the Himalayas and parts of North America during DJF and JJA, as well as Australia and South America in JJA, irrespective of whether MED or LEU is used. Unsurprisingly, to first order, the parameterization of $g_{\mathrm{s}}$ does not resolve the largescale biases in ACCESS1.3b. The differences between the two experiments (MED-LEU) however demonstrate an improvement in the $T_{\mathrm{MAX}}$ bias over the boreal forests in JJA of up to $1^{\circ} \mathrm{C}$, but the positive bias over North America is increased. MED also leads to warming, relative to LEU, of $\sim 0.3{ }^{\circ} \mathrm{C}$ over the regions of tropical forest over South America and Africa. A large region of Eurasia warms with MED in DJF by $\sim 0.3{ }^{\circ} \mathrm{C}$, reducing the bias in ACCESS1.3b. Figure 3 shows the same results but for $T_{\mathrm{MIN}}$ and the results are broadly similar to the $T_{\mathrm{MAX}}$ results. Specifically, the inherent biases within ACCESS1.3b remain and the net effect of the
MED $g_{\mathrm{s}}$ scheme is a small overall increase in the biases associated with $T_{\mathrm{MIN}}$. However, the simulation of $T_{\mathrm{MIN}}$ is worsened in some regions, particularly in JJA over North America, likely linked with poor simulations of cloud (Franklin et al., 2013).

Having examined the influence of the new $g_{\mathrm{s}}$ scheme on $T_{\mathrm{MAX}}$ and $T_{\mathrm{MIN}}$, we now focus on two extreme temperature indices based on $T_{\mathrm{MAX}}$ and $T_{\mathrm{MIN}}$, namely, the warmest $T_{\mathrm{MAX}}$ of the year ( $T_{X x}$, Fig. 4) and DTR (Fig. 5). ACCESS1.3b has a systematic cold bias in $T_{X X}$ in both DJF (Fig. 4c) and JJA (Fig. 4d) using LEU. In both seasons, this cold bias commonly exceeds $10^{\circ} \mathrm{C}$. Replacing LEU with MED reduces this cold bias by up to $20 \%$ over Eurasia and parts of North America. The MED-LEU difference (Fig. 4e, f) is almost always positive, implying a reduced error over most of the globe using MED. Remarkably, a large region of warm bias to the north-east of the Mediterranean cools with MED relative to LEU in JJA (Fig. 4f) reducing this bias by $\sim 20 \%$. While clearly not resolving all biases in $T_{X x}$, replacing LEU with MED clearly leads to improvements and has a regional impact that helps reduce both positive and negative biases in the model.

One of the errors identified by Lorenz et al. (2014) was an unsatisfactory simulation of the diurnal temperature range (DTR). Figure 5 shows little impact by switching to MED in DJF, but in JJA there are large areas of the Northern Hemi- 

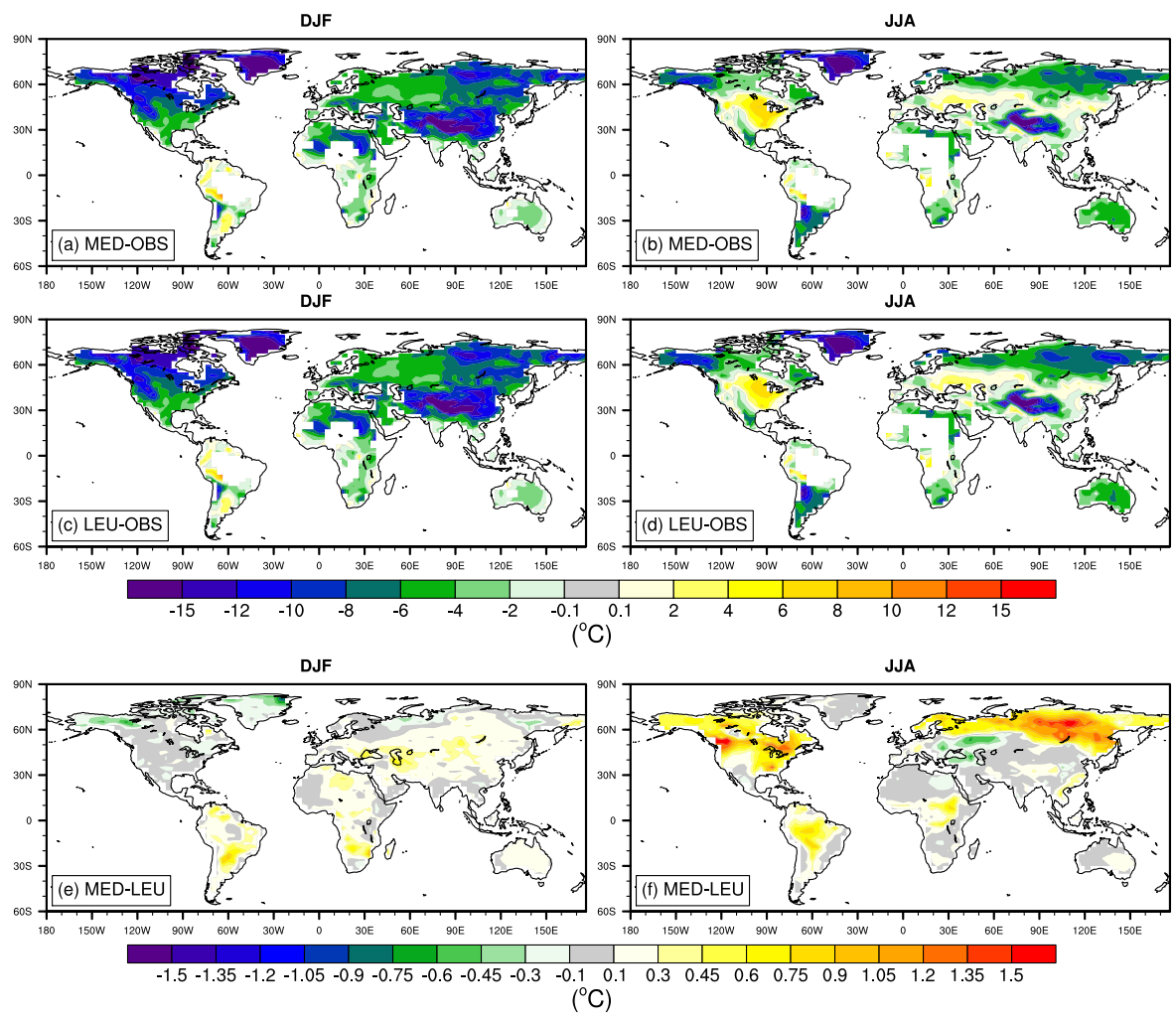

Figure 4. Same as in Fig. 2 except for the warmest maximum $\left(T_{X x}\right)$. Observations are from the HadEX2 data set and seasonal means are computed over the period 1960-2010.

sphere, coincident with the boreal forests, where the $3-5^{\circ} \mathrm{C}$ error in DTR is reduced by $10-20 \%$. This is caused the by larger increase in $T_{\text {MAX }}$ (Fig. 2f) versus $T_{\text {MIN }}$ (Fig. 3f). Clearly, using MED does not resolve ACCESS's limitations in capturing the observed DTR, but the magnitude of the error is reduced.

The change in the $g_{\mathrm{s}}$ parameterization has the most immediate effect on vegetation transpiration (here represented as part of the total moisture flux, evapotranspiration, ET). Figure 6 shows comparisons between the two experiments and the LandFlux ET as well as the differences between the two simulations. There are two major regions where MED leads to reduced ET. Over the boreal forests, ET is reduced by $\sim 0.1-0.3 \mathrm{~mm} \mathrm{day}^{-1}$ which reduces the high ET bias seen in LEU (Fig. 6c, d). MED also reduces ET in the tropical forest regions by $\sim 0.1 \mathrm{~mm} \mathrm{day}^{-1}$ again generally reducing the bias seen in LEU. There are regions where the use of MED degrades the simulation (relative to the LandFlux product), for example over eastern Australia in DJF and through the croplands of western and eastern Europe.

The changes in ET directly affect total precipitation (Fig. 7). In DJF, ACCESS1.3b has a wet bias over Amazonia and southern Africa and these biases are reduced using MED. In JJA ACCESS1.3b has a wet bias over the boreal forests and a dry bias over the region to the north-east of the
Mediterranean. Replacing LEU with MED reduces this wet bias over the boreal forests by $\sim 10 \%$ but does not resolve the bias to the north-east of the Mediterranean. A wet bias in JJA is also reduced (Fig. 7f) in areas of the tropics. In addition to affecting the elements of the hydrological cycle through precipitation, the reduced ET also affects the terrestrial carbon balance via the net primary productivity (NPP; Fig. 8).

The reduction in $g_{\mathrm{s}}$ also results in an associated reduction in NPP across the boreal forests in JJA (Fig. 8b) and in the tropics in both JJA and DJF (Fig. 8). This reduction in NPP is also a result of a change in precipitation across these regions, which results from a reduction in ET due to $g_{s}$. There is also an increase in NPP in JJA in the region to the north and east of the Mediterranean, consistent with an increase in ET in this region (Fig. 6f) using MED.

\section{Discussion}

We implemented a new $g_{\mathrm{s}}$ scheme within the ACCESS global climate model by modifying the CABLE LSM. The new scheme, MED, has advantages over the LEU scheme in being founded on optimisation theory and utilising a database of stomatal conductance data (Lin et al., 2015) with a reasonable, if heterogeneous, spatial coverage. The MED $g_{\mathrm{s}}$ scheme 

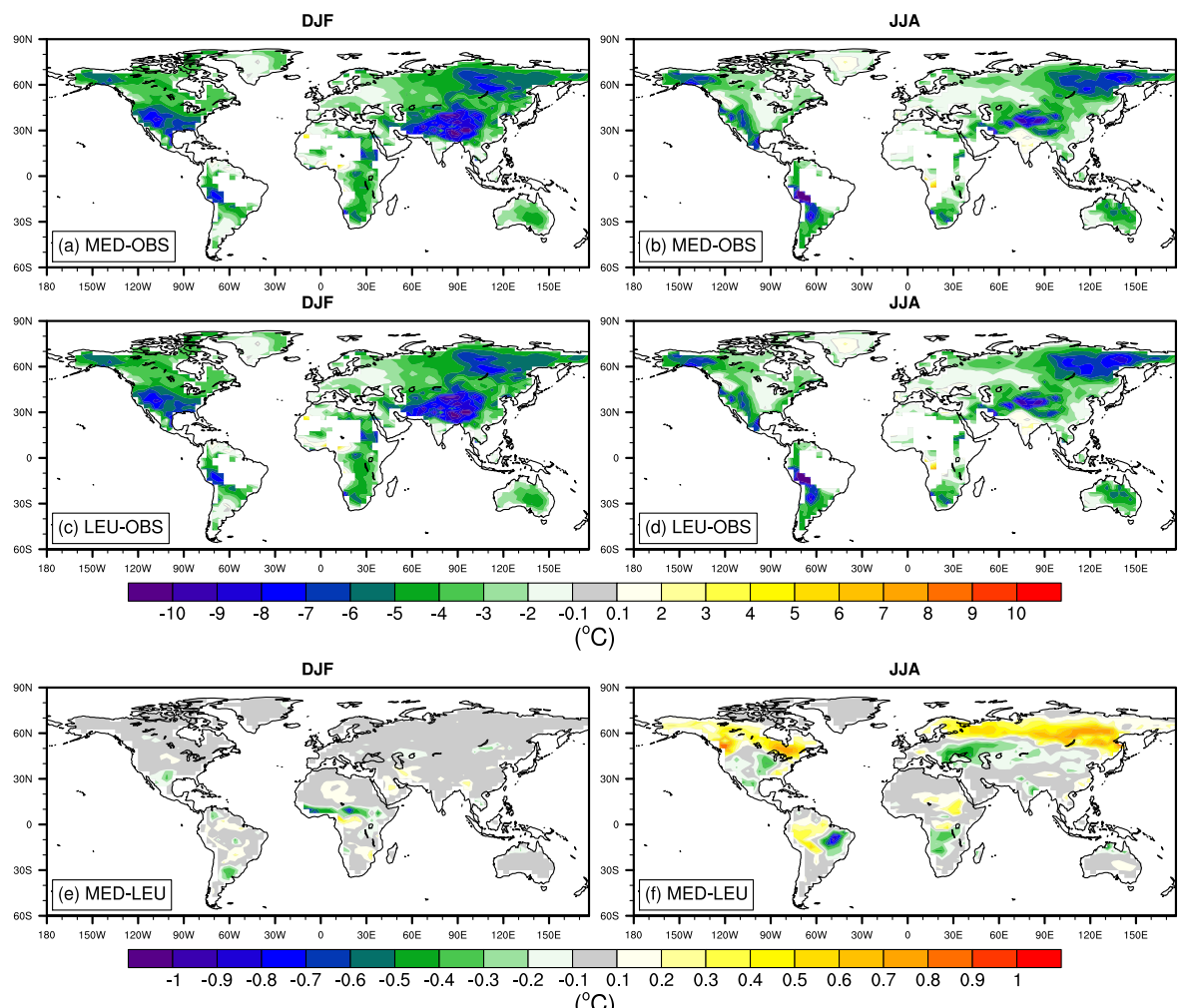

$\left({ }^{\circ} \mathrm{C}\right)$

Figure 5. Same as in Fig. 4 except showing the diurnal temperature range (DTR) from the HadEX2 data set.

also has an advantage in that it improves the performance of CABLE's simulation of ET in offline studies, particularly for boreal forests, against a wide range of flux station observations as well as global offline simulations forced by reanalysis (De Kauwe et al., 2015). One aim of this paper was to determine if the MED $g_{\mathrm{s}}$ scheme would show similar improvements within the ACCESS1.3b climate model.

Our results show, first and foremost, that replacing LEU with MED results in an overall decrease in ET by $0.1-$ $0.3 \mathrm{~mm} \mathrm{day}^{-1}$ and a subsequent warming signal of up to $1{ }^{\circ} \mathrm{C}$, mostly over most parts of the world. Over the boreal forests, this is an overall improvement in this modelling system. However, the overall decrease in ET does not drastically change the overall climatology of ACCESS at the global scale. Modelling groups using parameterisations based on approaches similar to LEU are unlikely to result in major errors in the simulation of the present day. However, at regional scales, in particular in the boreal forests and to a lesser degree in the tropical forests using MED in ACCESS does reduce systematic model biases in $T_{\mathrm{MAX}}, T_{X x}$ and in rainfall. This is achieved with few decreases in model skill although one notable exception is North America. It is noteworthy that the largest improvements are in the most extreme metrics used for temperature, suggesting that, while MED may not make a major impact on the mean temperature, it does affect $T_{\mathrm{MAX}}$ and $T_{\mathrm{MIN}}$, and affects $T_{X x}$ quite strongly. We suspect that the increase in $T_{\mathrm{MIN}}$ is a residual effect of the increases in $T_{\mathrm{MAX}}$ and $T_{X x}$ during the day as differences in $g_{\mathrm{s}}$ are likely to be minimal at night-time. In summary, we note MED is clearly not a solution to all systematic biases in ACCESS and while we see general improvements in temperature, biases remain in some regions and are amplified in North America. We plan to examine the impact of using MED in the simulation of future temperature extremes in forthcoming work.

Replacing LEU with MED reduces ET (Fig. 6) in the boreal forests and to a lesser degree in the tropics. These changes are of a similar order of magnitude but generally smaller than those reported by De Kauwe et al. (2015) in their offline simulations with the MED $g_{\mathrm{s}}$ in CABLE. This reduction in ET results from the lower $g_{1}$ used in this region, which reflects a more conservative water use strategy by the vegetation (Lin et al., 2015), and the resulting lower $g_{\mathrm{s}}$ reduces ET. This reduction in ET varies between vegetation types and in CABLE there tends to be a stronger impact on boreal regions (coniferous evergreen forest) in comparison to grasslands and crops. All subsequent results are a direct consequence of this first-order impact in ET. The reduction in ET reduces the latent heat flux and, by energy balance constraints, increases the sensible heat flux. This modification to the surface energy balance leads to surface warming. Since this tends to be amplified during the day when net radiation is higher we see a stronger impact on $T_{\mathrm{MAX}}$ than $T_{\mathrm{MIN}}$, and 

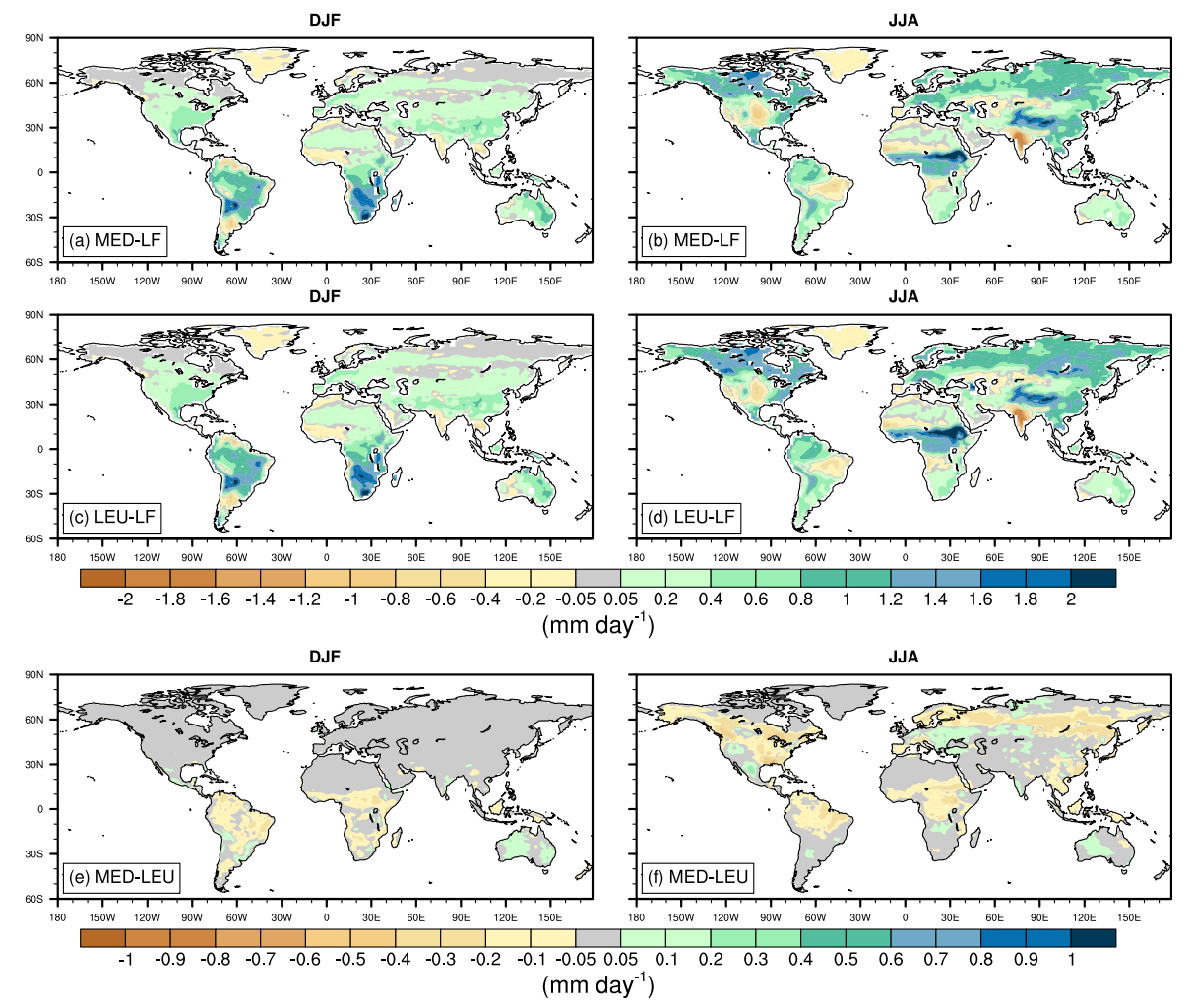

Figure 6. Same as in Fig. 2 except for evapotranspiration (ET). Multi-model estimates are from the LandFlux (LF) data set and seasonal means are computed over the period 1989-2005.

since the impact of reduced latent heat can have a proportionally stronger impact on temperature extremes we see a larger impact on $T_{X x}$. The lower latent heat flux means a lower moisture flux into the atmosphere, which tends to reduce precipitation. The lower ET also reduces the capacity of the vegetation to fix carbon and tends to lead to lower net primary productivity.

It is worth commenting on why the change in ET (Fig. 6) is generally smaller in our coupled experiments in comparison to the offline results reported by De Kauwe et al. (2015). Coupling a LSM to an atmosphere introduces feedbacks; a change in ET can impact rainfall, as found in our results, but it can also impact cloud cover, incoming solar radiation and thereby net radiation. These feedbacks are complex and examining the relative contributions of each component requires an explicit experimental design and the storage of variables that we did not attempt here because it was beyond the scope of our study. It would be useful, in the future, to examine how the change in conductance directly affects ET in contrast to how it triggers feedbacks that indirectly affect ET.

We note that the differences shown here between LEU and MED most likely predominately result from the new spatial varying $g_{1}$ parameter values (Fig. 1, Table 1) rather than the different structures of the $g_{\mathrm{s}}$ models (Eqs. 1, 3). De Kauwe et al. (2015) used offline global simulations to investigate the relative roles of structure vs. parameterisation, concluding that structure only resulted in small differences in ET estimates. We also note that a limitation of our work is that we use a prescribed LAI climatology, a common approach in global climate models. It is highly likely that the use of prognostic LAI will result in larger differences between the two schemes and this will be subject to future work. For example Piao et al. (2006) have shown using a global dynamic vegetation model that changes in climate and ambient $\mathrm{CO}_{2}$ strongly influence greening trends in the Northern Hemisphere $\left(>25^{\circ} \mathrm{N}\right)$. Our use of a prescribed monthly LAI climatology does not allow for such feedbacks and, additionally, MODIS LAI has known inaccuracies over forested regions (e.g. Shabanov et al., 2005; De Kauwe et al., 2011; Sea et al., 2011; Serbin et al., 2013).

The ACCESSv1.3 model is a skillful global climate model, performing at the top end in the evaluation of CMIP5 models (Flato et al., 2013). While the model's overall climatology is very good, there are regional systematic biases that exist irrespective of whether the LEU or MED scheme is used. However, we note that MED does make the model worse in some regions. Perhaps the most serious bias in temperature is over North America in summer (Figs. 2-4). The biases in ACCESS using LEU reach $5-7^{\circ} \mathrm{C}$ in $T_{\mathrm{MAX}}, 8_{-}$ $9^{\circ} \mathrm{C}$ in $T_{\mathrm{MIN}}$ and $6-8{ }^{\circ} \mathrm{C}$ in $T_{X x}$. Using MED makes these biases worse, by $\sim 0.5^{\circ} \mathrm{C}$ for $T_{\mathrm{MAX}}$ and $T_{\mathrm{MIN}}$ and by $\sim 1{ }^{\circ} \mathrm{C}$ for $T_{X x}$. Given the magnitude of the error in ACCESS, we 

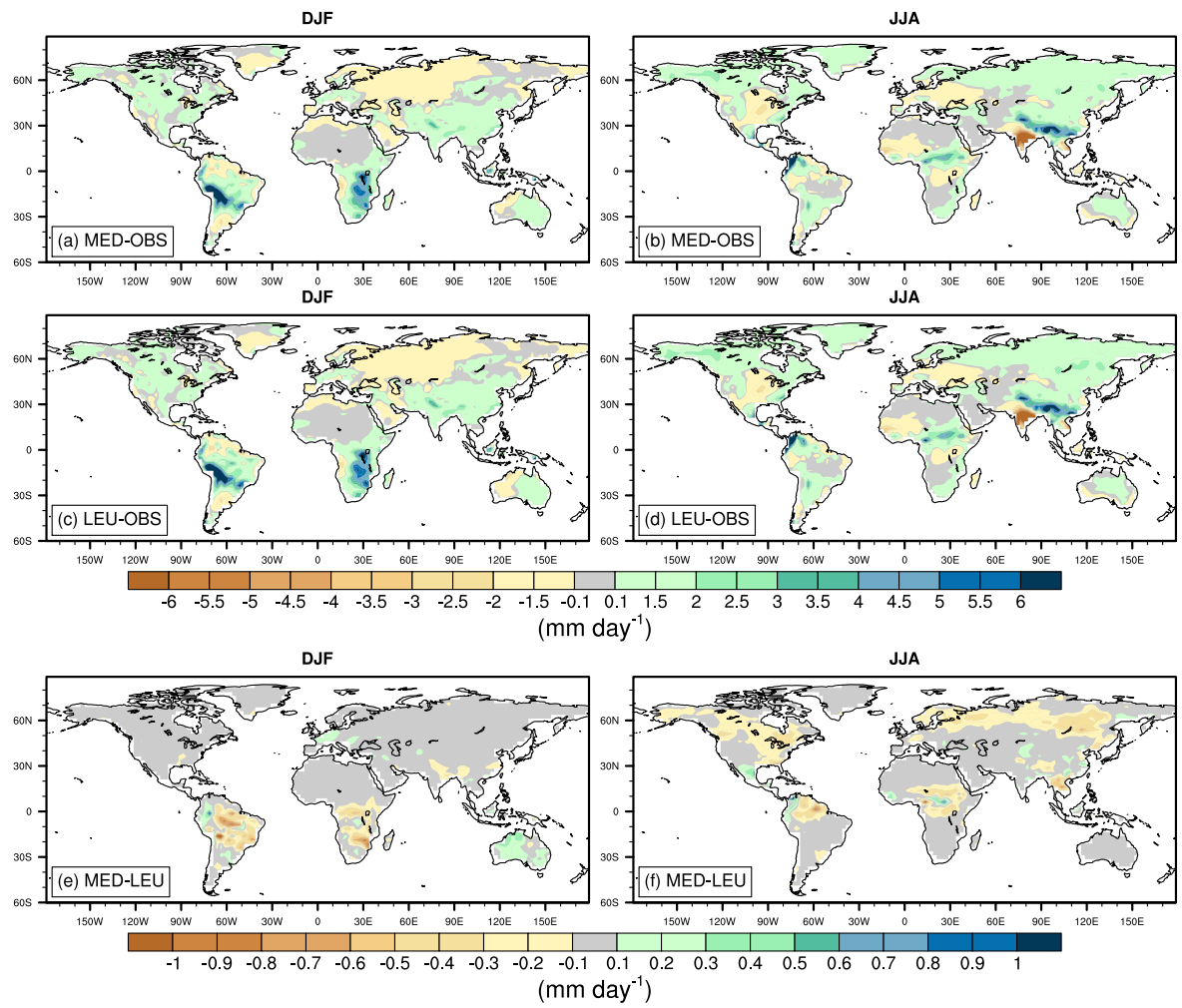

Figure 7. Same as in Fig. 2 except for total precipitation. Observations are from the GPCP data set and seasonal means are computed over the period 1979-2011.

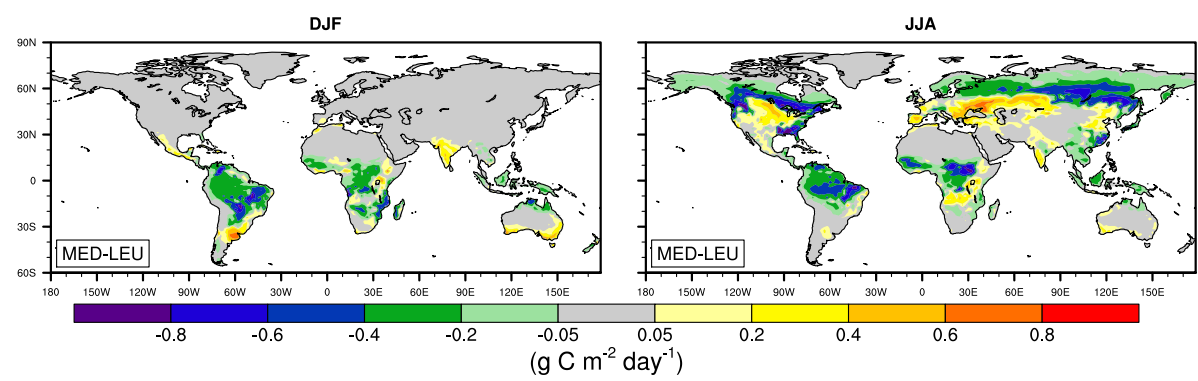

Figure 8. Mean seasonal difference in net primary productivity between the MED and LEU simulations.

suggest that using MED does not really make the model significantly worse since it is already very poor in this region. The poor performance of ACCESS over North America, across several model versions, has been previously reported. Bi et al. (2013) show errors of $3-4{ }^{\circ} \mathrm{C}$ in the mean air temperature over North America. This does not appear to be linked with low rainfall but rather appears linked with an underestimation of cloud coverage over North America despite the overall tendency to simulate slightly too much cloud over Northern Hemisphere land (Bi et al., 2013). Franklin et al. (2013) examined ACCESS1.3's simulation of clouds but did not focus specifically on North America. They did note problems with capturing convective regimes; these showed too weak a dependence on large-scale dynamics in comparison to observations. The change from the LEU to the MED scheme would not be expected to affect large-scale dynamics or how these processes affect clouds. Small decreases in ACCESS's skill in capturing North America's climate linked with the MED scheme are very likely insignificant; if the large-scale cloud fields were simulated well, MED might make a small positive impact in this region but any benefits are currently swamped by the poor cloud climatology. A similar problem exists over the Indian monsoon region where there is a very serious rainfall bias (Fig. 7). The MED scheme does not add value here because there are major systematic weaknesses in the generation of the monsoon linked with larger-scale dynamics as distinct from terrestrial processes. 
Finally, we note that other land surface modelling groups are also moving towards replacing the empirical scheme of $g_{\mathrm{s}}$ with schemes that explicitly account for optimal behaviour. For example, Bonan et al. (2014) replaced the original empirical stomatal conductance model (Ball et al., 1987) within the Community Land Model with a numerical scheme based on Williams et al. (1996), which optimises carbon gain per unit of water loss while also limiting stomatal opening to prevent leaf water potential from dropping below critical levels. This has been shown to improve simulations offline, similar to De Kauwe et al. (2015). Our implementation differs in that we use an analytical solution and account for soil-water limitation via the empirical scalar relationship in Eq. (2), rather than solve for it numerically. Nonetheless, the $g_{\mathrm{s}}$ model presented here can be extended to other LSMs both offline and coupled, but would require a subjective mapping of $g_{1}$ to PFT classifications used by different LSM groups.

\section{Conclusions}

We had two goals for this paper. First, we sought to test the feasibility of using the Medlyn et al. (2011) stomatal conductance scheme, based on optimal stomatal theory, within the ACCESS global climate model. We have demonstrated that this is feasible. Our second goal was to determine whether the improvements found by using the Medlyn et al. (2011) stomatal conductance scheme in offline simulations (De Kauwe et al., 2015) were also found in the ACCESS1.3b coupled model. We have shown that, by reducing evapotranspiration, temperatures increased which generally reduces associated biases by around 10-20\% over the boreal forests. Maximum temperatures are generally improved, but major error systematic biases in minimum temperatures remain and are in some cases made worse. This can be expected as ACCESS is known to systematically over-predict minimum temperatures, and the net effect of the MED scheme is an overall warming due to a reduction in ET. Lorenz et al. (2014) linked the biases in $T_{\mathrm{MIN}}$ to systematic biases in incoming longwave radiation; hence, we expect that future improvements within ACCESS's atmospheric component will resolve this.

The reduction in evapotranspiration also affects rainfall, generally reducing some regional-scale biases. This also affects net primary productivity, with regions of decrease (increase) in evapotranspiration corresponding to regions of decrease (increase) in net primary production. The majority of these changes are clearly associated with boreal forest regions, but areas of the tropics and to a lesser degree areas of croplands in Eurasia are also affected. Using the Medlyn et al. (2011) stomatal conductance scheme therefore helps to address and improve aspects of the ACCESS1.3b model and also helps to address some of the extremes biases found by Lorenz et al. (2014). However, while some of the systematic biases are reduced, they were not fully resolved and thus other major problems must exist in the ACCESS-CABLE system.

The Medlyn et al. (2011) stomatal conductance scheme is founded in ecological theory, it adds skill to our global model and has the potential to be developed further to account for physiological responses to climate change and increasing atmospheric $\mathrm{CO}_{2}$. Our implementation of the optimal model has one key parameter, $g_{1}$, which is related to the marginal carbon cost of water. It is potentially possible to use theoretical considerations to predict how this parameter should vary among PFTs and with mean annual climate (e.g. Prentice et al., 2014; Lin et al., 2015). For example, Lin et al. (2015) demonstrated a significant relationship $\left(r^{2}=0.89\right)$ between $g_{1}$ and two long-term average (1960-1990) bioclimatic variables: temperature and a moisture index representing an indirect estimate of plant water availability. This implies that links between changing temperature and moisture could, in principle, be built into MED (De Kauwe et al., 2015). For example, in future, there is the potential to build a framework that enables ecophysiology research utilising flux tower observations to be more strongly coupled with global climate modelling via the use of parameterization schemes which are more founded in observations. There is considerable likelihood that $g_{\mathrm{s}}$ schemes built on new theory and informed by observations would affect how the terrestrial carbon balance responds to climate change and the direct forcing by increased atmospheric $\mathrm{CO}_{2}$. Given these advantages, we plan to use it in CABLE since we expect that it provides a framework for longer-term, more flexible, more data informed and more successful future model developments in the long term than alternative schemes. Future work will focus on the impact of the new scheme on future climate simulations under different representative concentration pathway scenarios.

\section{Code availability}

The CABLE source code is publicly available upon registration at https://trac.nci.org.au/trac/cable. The modified version of CABLE with the new $g_{\mathrm{s}}$ scheme can be viewed and accessed by registered users at https://trac.nci.org.au/trac/cable/browser/branches/ Share/CABLE-2.0.1-Tagged-plus-Medlyn-Stom-Param.

The ACCESS model source code is not publicly available but information can be found at https://accessdev.nci.org.au/trac/wiki/access.

Acknowledgements. This work was supported by the Australian Research Council Centre of Excellence for Climate System Science (CE110001028) and the NSW Environment Trust (RM08603). We thank the National Computational Infrastructure at the Australian National University, an initiative of the Australian Government, for access to supercomputer resources. We thank CSIRO and the Bureau of Meteorology through the Centre for Australian Weather and Climate Research for their support in the use of the CABLE and ACCESS models. 
The GPCP combined precipitation data were developed and computed by the NASA/Goddard Space Flight Center's Laboratory for Atmospheres as a contribution to the GEWEX Global Precipitation Climatology Project. GPCP data provided by the NOAA/OAR/ESRL PSD, Boulder, Colorado, USA, from their website at http://www.esrl.noaa.gov/psd/. This study uses the LandFluxEVAL merged benchmark synthesis products of ETH Zurich produced under the aegis of the GEWEX and ILEAPS projects (http: //www.iac.ethz.ch/groups/seneviratne/research/LandFlux-EVAL). Comments from two anonymous reviewers helped to improve the manuscript. All this assistance is gratefully acknowledged.

Edited by: G. A. Folberth

\section{References}

Avissar, R. and Pielke, R.: The impact of plant stomatal control on mesoscale atmospheric circulations, Agr. Forest Meteorol., 54, 353-372, doi:10.1016/0168-1923(91)90013-G, 1991.

Ball, J. T., Woodrow, I. E., and Berry, J. A.: A model predicting stomatal conductance and its contribution to the control of photosynthesis, in: Progress in photosynthesis research: proceedings of the VIIth International Congress on Photosynthesis, 10-15 August 1986, Rhode Island, USA, 221-224, 1987.

Bi, D., Dix, M., Marsland, S. J., Farrell, S. O., Rashid, H. A., Uotila, P., Hirst, A. C., Kowalczyk, E., Golebiewski, M., Sullivan, A., Yan, H., Hannah, N., Franklin, C., Sun, Z., Vohralik, P., Watterson, I., Zhou, X., Fiedler, R., Collier, M., Ma, Y., Noonan, J., Stevens, L., Uhe, P., Zhu, H., Griffies, S. M., Hill, R., Harris, C., and Puri, K.: The ACCESS coupled model: description, control climate and evaluation, Aust. Meteorol. Ocean. J., 63, 9-32, 2013.

Bonan, G. B.: Land-atmosphere $\mathrm{CO}_{2}$ exchange simulated by a land surface process model coupled to an atmospheric general circulation model, J. Geophys. Res.-Atmos., 100, 2817-2831, doi:10.1029/94JD02961, 1995.

Bonan, G. B., Williams, M., Fisher, R. A., and Oleson, K. W.: Modeling stomatal conductance in the earth system: linking leaf water-use efficiency and water transport along the soil-plantatmosphere continuum, Geosci. Model Dev., 7, 2193-2222, doi:10.5194/gmd-7-2193-2014, 2014.

Caesar, J., Alexander, L., and Vose, R.: Large-scale changes in observed daily maximum and minimum temperatures: creation and analysis of a new gridded data set, J. Geophys. Res.-Atmos., 111, D05101, doi:10.1029/2005JD006280, 2006.

Cox, P., Huntingford, C., and Harding, R.: A canopy conductance and photosynthesis model for use in a GCM land surface scheme, J. Hydrol., 212-213, 79-94, doi:10.1016/S0022-1694(98)00203$0,1998$.

Cruz, F. T., Pitman, A. J., and Wang, Y.-P.: Can the stomatal response to higher atmospheric carbon dioxide explain the unusual temperatures during the 2002 Murray-Darling Basin drought?, J. Geophys. Res., 115, D02101, doi:10.1029/2009JD012767, 2010.

Davies, T., Cullen, M. J. P., Malcolm, A. J., Mawson, M. H., Staniforth, A., White, A. A., and Wood, N.: A new dynamical core for the Met Office's global and regional modelling of the atmosphere, Q. J. Roy. Meteor. Soc., 131, 1759-1782, doi:10.1256/qj.04.101, 2005. de Boer, H. J., Lammertsma, E. I., Wagner-Cremer, F., Dilcher, D. L., Wassen, M. J., and Dekker, S. C.: Climate forcing due to optimization of maximal leaf conductance in subtropical vegetation under rising $\mathrm{CO}_{2}$, P. Natl. Acad. Sci. USA, 108, 4041-4046, doi:10.1073/pnas.1100555108, 2011.

De Kauwe, M. G., Disney, M., Quaife, T., Lewis, P., and Williams, M.: An assessment of the MODIS collection 5 leaf area index product for a region of mixed coniferous forest, Remote Sens. Environ., 115, 767-780, doi:10.1016/j.rse.2010.11.004, 2011.

De Kauwe, M. G., Kala, J., Lin, Y.-S., Pitman, A. J., Medlyn, B. E., Duursma, R. A., Abramowitz, G., Wang, Y.-P., and Miralles, D. G.: A test of an optimal stomatal conductance scheme within the CABLE land surface model, Geosci. Model Dev., 8, 431-452, doi:10.5194/gmd-8-431-2015, 2015.

Donat, M. G., Alexander, L. V., Yang, H., Durre, I., Vose, R., Dunn, R. J. H., Willett, K. M., Aguilar, E., Brunet, M., Caesar, J., Hewitson, B., Jack, C., Klein Tank, A. M. G., Kruger, A. C., Marengo, J., Peterson, T. C., Renom, M., Oria Rojas, C., Rusticucci, M., Salinger, J., Elrayah, A. S., Sekele, S. S., Srivastava, A. K., Trewin, B., Villarroel, C., Vincent, L. A., Zhai, P., Zhang, X., and Kitching, S.: Updated analyses of temperature and precipitation extreme indices since the beginning of the twentieth century: the HadEX2 dataset, J. Geophys. Res.Atmos., 118, 2098-2118, doi:10.1002/jgrd.50150, 2013.

Flato, G., Marotzke, J., Abiodun, B., Braconnot, P., Chou, S., Collins, W., Cox, P., Driouech, F., Emori, S., Eyring, V., Forest, C., Gleckler, P., Guilyardi, E., Jakob, C., Kattsov, V., Reason, C., and Rummukainen, M.: Evaluation of climate models, in: Climate Change 2013: The Physical Science Basis. Contribution of Working Group I to the Fifth Assessment Report of the Intergovernmental Panel on Climate Change, edited by: Stocker, T. F., Qin, D., Plattner, G.-K., Tignor, M., Allen, S. K., Boschung, J., Nauels, A., Xia, Y., Bex, V., and Midgley, P. M., Cambridge University Press, Cambridge, UK and New York, NY, USA, 741-866, 2013.

Franklin, C. N., Sun, Z., Bi, D., Dix, M., Yan, H., and Bodas-Salcedo, A.: Evaluation of clouds in ACCESS using the satellite simulator package COSP: regime-sorted tropical cloud properties, J. Geophys. Res.-Atmos., 118, 6663-6679, doi:10.1002/jgrd.50496, 2013.

Gates, W. L.: AMIP: the Atmospheric Model Intercomparison Project, B. Am. Meteorol. Soc., 73, 1962-1970, 1992.

Henderson-Sellers, A., Pitman, A. J., Love, P. K., Irannejad, P., and Chen, T. H.: The Project for Intercomparison of Land Surface Parameterization Schemes (PILPS): phases 2 and 3, B. Am. Meteorol. Soc., 76, 489-503, 1995.

Huntingford, C. and Monteith, J.: The behaviour of a mixed-layer model of the convective boundary layer coupled to a big leaf model of surface energy partitioning, Bound.-Lay. Meteorol., 88, 87-101, doi:10.1023/A:1001110819090, 1998.

Huntingford, C., Zelazowski, P., Galbraith, D., Mercado, L. M., Sitch, S., Fisher, R., Lomas, M., Walker, A. P., Jones, C. D., Booth, B. B. B., Malhi, Y., Hemming, D., Kay, G., Good, P., Lewis, S. L., Phillips, O. L., Atkin, O. K., Lloyd, J., Gloor, E., Zaragoza-Castells, J., Meir, P., Betts, R., Harris, P. P., Nobre, C., Marengo, J., and Cox, P. M.: Simulated resilience of tropical rainforests to $\mathrm{CO}_{2}$-induced climate change, Nat. Geosci., 6, 268273, 2013. 
Huntingford, C., Smith, D. M., Davies, W. J., Falk, R., Sitch, S., and Mercado, L. M.: Combining the [ABA] and net photosynthesisbased model equations of stomatal conductance, Ecol. Model., 300, 81-88, doi:10.1016/j.ecolmodel.2015.01.005, 2015.

Jacobs, C. M. J. and De Bruin, H. A. R.: The sensitivity of regional transpiration to land-surface characteristics: significance of feedback, J. Climate, 5, 683-698, doi:10.1175/15200442(1992)005<0683:TSORTT>2.0.CO;2, 1992.

Jarvis, P. G.: The interpretation of the variations in leaf water potential and stomatal conductance found in canopies in the field, Philos. T. Roy. Soc. B, 273, 593-610, doi:10.1098/rstb.1976.0035, 1976.

Kowalczyk, E. A., Stevens, L., Law, R. M., Dix, M., Wang, Y. P., Harman, I. N., Haynes, K., Srbinovsky, J., Pak, B., and Ziehn, T.: The land surface model component of ACCESS: description and impact on the simulated surface climatology, Aust. Meteorol. Ocean. J., 63, 65-82, 2013.

Krinner, G., Viovy, N., de Noblet-Ducoudré, N., Ogée, J., Polcher, J., Friedlingstein, P., Ciais, P., Sitch, S., and Prentice, I. C.: A dynamic global vegetation model for studies of the coupled atmosphere-biosphere system, Global Biogeochem. Сy., 19, GB1015, doi:10.1029/2003GB002199, 2005.

Leuning, R.: A critical appraisal of a combined stomatalphotosynthesis model for C3 plants, Plant Cell Environ., 18, 339-355, doi:10.1111/j.1365-3040.1995.tb00370.x, 1995.

Lin, Y.-S., Medlyn, B. E., Duursma, R. A., Prentice, I. C., Wang, H., Baig, S., Eamus, D., de Dios, V. R., Mitchell, P., Ellsworth, D. S., de Beeck, M. O., Wallin, G., Uddling, J., Tarvainen, L., Linderson, M.-L., Cernusak, L. A., Nippert, J. B., Ocheltree, T. W., Tissue, D. T., Martin-StPaul, N. K., Rogers, A., Warren, J. M., De Angelis, P., Hikosaka, K., Han, Q., Onoda, Y., Gimeno, T. E., Barton, C. V. M., Bennie, J., Bonal, D., Bosc, A., Low, M., Macinins-Ng, C., Rey, A., Rowland, L., Setterfield, S. A., Tausz-Posch, S., Zaragoza-Castells, J., Broadmeadow, M. S. J., Drake, J. E., Freeman, M., Ghannoum, O., Hutley, L. B., Kelly, J. W., Kikuzawa, K., Kolari, P., Koyama, K., Limousin, J.M., Meir, P., Lola da Costa, A. C., Mikkelsen, T. N., Salinas, N., Sun, W., and Wingate, L.: Optimal stomatal behaviour around the world, Nature Clim. Change, 5, 459-464, 2015.

Lorenz, R., Pitman, A. J., Donat, M. G., Hirsch, A. L., Kala, J., Kowalczyk, E. A., Law, R. M., and Srbinovsky, J.: Representation of climate extreme indices in the ACCESS1.3b coupled atmosphere-land surface model, Geosci. Model Dev., 7, 545567, doi:10.5194/gmd-7-545-2014, 2014.

Martin, G. M., Ringer, M. A., Pope, V. D., Jones, A., Dearden, C., and Hinton, T. J.: The physical properties of the atmosphere in the New Hadley Centre Global Environmental Model (HadGEM1). Part I: Model description and global climatology, J. Climate, 19, 1274-1301, doi:10.1175/JCLI3636.1, 2006.

Martin, M., Dickinson, R. E., and Yang, Z.-L.: Use of a coupled land surface general circulation model to examine the impacts of doubled stomatal resistance on the water resources of the American Southwest, J. Climate, 12, 3359-3375, 1999.

Medlyn, B. E., Duursma, R. A., Eamus, D., Ellsworth, D. S., Prentice, I. C., Barton, C. V. M., Crous, K. Y., De Angelis, P., Freeman, M., and Wingate, L.: Reconciling the optimal and empirical approaches to modelling stomatal conductance, Glob. Change Biol., 17, 2134-2144, doi:10.1111/j.1365-2486.2010.02375.x, 2011.
Mueller, B., Hirschi, M., Jimenez, C., Ciais, P., Dirmeyer, P. A., Dolman, A. J., Fisher, J. B., Jung, M., Ludwig, F., Maignan, F., Miralles, D. G., McCabe, M. F., Reichstein, M., Sheffield, J., Wang, K., Wood, E. F., Zhang, Y., and Seneviratne, S. I.: Benchmark products for land evapotranspiration: LandFluxEVAL multi-data set synthesis, Hydrol. Earth Syst. Sci., 17, 3707-3720, doi:10.5194/hess-17-3707-2013, 2013.

Oleson, K. W., Lawrence, D. M., Bonan, G. B., Drewniak, B., Huang, M., Koven, C. D., Levis, S., Li, F., Riley, W. J., Subin, Z. M., Swenson, S. C., Thornton, P. E., Bozbiyik, A., Fisher, R., Heald, C. L., Kluzek, E., Lamarque, J.-F., Lawrence, P. J., Leung, L. R., Lipscomb, W., Muszala, S., Ricciuto, D. M., Sacks, W., Sun, Y., Tang, J., and Yang, Z.-L.: Technical description of version 4.5 of the Community Land Model (CLM), National Center for Atmosperic Research Earth System Laboratory, Climate and Global Dynamics Division, NCAR/TN-503+STR Technical Note, Boulder, Colorado, USA, 2013.

Piao, S., Friedlingstein, P., Ciais, P., Zhou, L., and Chen, A.: Effect of climate and $\mathrm{CO}_{2}$ changes on the greening of the Northern Hemisphere over the past two decades, Geophys. Res. Lett., 33, L23402, doi:10.1029/2006GL028205, 2006.

Pitman, A. J.: The evolution of, and revolution in, land surface schemes designed for climate models, Int. J. Climatol., 23, 479510, doi:10.1002/joc.893, 2003.

Pollard, D. and Thompson, S. L.: Use of a land-surface-transfer scheme (LSX) in a global climate model: the response to doubling stomatal resistance, Global Planet. Change, 10, 129-161, doi:10.1016/0921-8181(94)00023-7, 1995.

Prentice, I. C., Dong, N., Gleason, S. M., Maire, V., and Wright, I. J.: Balancing the costs of carbon gain and water transport: testing a new theoretical framework for plant functional ecology, Ecol. Lett., 17, 82-91, doi:10.1111/ele.12211, 2014.

Raupach, M. R.: Influences of local feedbacks on land-air exchanges of energy and carbon, Glob. Change Biol., 4, 477-494, doi:10.1046/j.1365-2486.1998.t01-1-00155.x, 1998.

Sea, W. B., Choler, P., Beringer, J., Weinmann, R. A., Hutley, L. B., and Leuning, R.: Documenting improvement in leaf area index estimates from MODIS using hemispherical photos for Australian savannas, Agr. Forest Meteorol., 151, 1453-1461, doi:10.1016/j.agrformet.2010.12.006, 2011.

Sellers, P., Berry, J., Collatz, G., Field, C., and Hall, F.: Canopy reflectance, photosynthesis, and transpiration. III. A reanalysis using improved leaf models and a new canopy integration scheme, Remote Sens. Environ., 42, 187-216, doi:10.1016/00344257(92)90102-P, 1992.

Sellers, P. J., Randall, D. A., Collatz, G. J., Berry, J. A., Field, C. B., Dazlich, D. A., Zhang, C., Collelo, G. D., and Bounoua, L.: A revised land surface parameterization $(\mathrm{SiB} 2)$ for atmospheric GCMS. Part I: Model formulation, J. Climate, 9, 676-705, 1996.

Serbin, S. P., Ahl, D. E., and Gower, S. T.: Spatial and temporal validation of the MODIS LAI and FPAR products across a boreal forest wildfire chronosequence, Remote Sens. Environ., 133, 7184, doi:10.1016/j.rse.2013.01.022, 2013.

Shabanov, N., Huang, D., Yang, W., Tan, B., Knyazikhin, Y., Myneni, R., Ahl, D., Gower, S., Huete, A., Aragao, L., and Shimabukuro, Y.: Analysis and optimization of the MODIS leaf area index algorithm retrievals over broadleaf forests, IEEE T. Geosci. Remote, 43, 1855-1865, doi:10.1109/TGRS.2005.852477, 2005. 
Taylor, K. E., Williamson, D., and Zwiers, F.: The Sea Surface Temperature and Sea-Ice Concentration Boundary Conditions For AMIP II Simulations, PCMDI Rep. No. 60, Livermore, California, USA, 2000.

Wang, Y.-P. and Leuning, R.: A two-leaf model for canopy conductance, photosynthesis and partitioning of available energy I: Model description and comparison with a multi-layered model, Agr. Forest Meteorol., 91, 89-111, doi:10.1016/S01681923(98)00061-6, 1998.

Wang, Y. P., Law, R. M., and Pak, B.: A global model of carbon, nitrogen and phosphorus cycles for the terrestrial biosphere, Biogeosciences, 7, 2261-2282, doi:10.5194/bg-7-2261-2010, 2010.
Wang, Y. P., Kowalczyk, E., Leuning, R., Abramowitz, G., Raupach, M. R., Pak, B., van Gorsel, E., and Luhar, A.: Diagnosing errors in a land surface model (CABLE) in the time and frequency domains, J. Geophys. Res.-Biogeo., 116, G01034, doi:10.1029/2010JG001385, 2011.

Williams, M., Rastetter, E. B., Fernandes, D. N., Goulden, M. L., Wofsy, S. C., Shaver, G. R., Melillo, J. M., Munger, J. W., Fan, S.-M., and Nadelhoffer, K. J.: Modelling the soil-plantatmosphere continuum in a Quercus-Acer stand at Harvard Forest: the regulation of stomatal conductance by light, nitrogen and soil/plant hydraulic properties, Plant Cell Environ., 19, 911-927, doi:10.1111/j.1365-3040.1996.tb00456.x, 1996. 